\title{
Perancangan Sliding Mode Controller Untuk Sistem Pengaturan Level Dengan Metode Decoupling Pada Plant Coupled Tanks
}

\author{
Boby Dwi Apriyadi dan Rusdhianto Effendie A.K. \\ Jurusan Teknik Elektro, Fakultas Teknologi Industri, Institut Teknologi Sepuluh Nopember (ITS) \\ Jl. Arief Rahman Hakim, Surabaya 60111 \\ e-mail: rusdhi@elect-eng.its.ac.id
}

\begin{abstract}
Abstrak-Pada industri proses yang melibatkan fluida, suatu fluida akan dipompa dan dialirkan dari satu tangki ke tangki yang lain untuk diolah. Pemindahan cairan dari satu tangki ke tangki yang lain meyebabkan berubahnya level fluida dalam tangki. Dalam pengaturan level, pemindahan cairan biasa disebut sebagai pembebanan pada level. Perubahan beban ini dapat mempengaruhi dari kinerja kontroler. Kontroler yang banyak digunakan di industri proses adalah kontroler PID karena kesederhanaan struktur dan kehandalannya. Sliding Mode Controller adalah suatu metodologi pengaturan yang mampu mengatasi perubahan yang mengganggu pada sistem, tanpa menyebabkan gangguan pada performa sistem itu sendiri. Struktur Sliding Mode Control terdiri dari bagian utama yang berfungsi memperbaiki sinyal error dengan mengarahkan sinyal tersebut pada sebuah lintasan yang diinginkan dan bagian tambahan yang berfungsi untuk mempertahankan sinyal, sehingga dapat mengatasi perubahan parameter pada plant dan menjaga performa dari plant. Berdasarkan hasil simulasi, sistem pengaturan level air pada plant coupled tank dengan Sliding Mode Controller mempunyai nilai RMSE $0.043 \%$.
\end{abstract}

Kata Kunci-Coupled Tank, Decoupling, Sliding Mode Control.

\section{PENDAHULUAN}

$\mathrm{S}$ ISTEM pengendalian di industri merupakan faktor yang sangat penting dalam proses produksi. Agar produksi tetap tercapai, maka suatu sistem pengendalian sangat diperlukan untuk menjaga kestabilan variable proses. Variabel proses antara lain flow, level, konsentrasi, volume, dan lain sebaagainya.

Coupled tanks merupakan salah satu bagian di industry yang memiliki fungsi yang sangat vital. Secara umum coupled tanks terdiri dari beberapa sistem, diantaranya adalah sistem umpan air, sistem flow, level yang terintegrasi menjadi satu kesatuan. Sistem umpan air berfungsi sebagai penyedia air untuk coupled tanks yang bekerja secara otomatis sesuai kebutuhan steam dan kemampuan dari coupled tanks itu sendiri. Sedangkan sistem steam berfungsi sebagai penyedia uap air untuk proses pada plant yang lain. Kedua sistem ini memerlukan suatu pengaturan agar kondisi flow dan level air dapat untuk memenuhi kebutuhan proses selanjutnya. Pengaturan air dilakukan dengan mengendalikian level air yang terdapat di dalam coupled tanks itu sendiri, sedangkan level air dilakukan dengan mengendalikan flow yang masuk ke dalam coupled tanks sendiri. Flow yang dihasilkan oleh coupled tanks dipengaruhi oleh kondisi dari level air tang terdapat di dalam coupled tanks.
Salah satu metode pengaturan yang digunakan untuk mengatasi ketidakpastian sistem yang dapat diaplikasikan pada plant ini adalah metode Sliding Mode Control yang adalah salah satu teknik kontrol yang dapat digunakan pada plant yang linier dan nonlinier. Prinsip dasar untuk Sliding Mode Control terdiri dari perpindahan atau pergerakan keadaan lintasan ke arah bidang geser (sliding surface) dan mempertahankannya sekitar bidang ini dengan sebuah fungsi geser.

Namun, metode Sliding Mode Control ini mempunyai kelemahan, yaitu timbulnya chattering atau switching dengan frekuensi tinggi pada sinyal kontrol, yang disebabkan oleh sifat diskontinyu pada sinyal kontrol natural dari sistem. Oleh karena itu, dalam penelitian kali ini akan digunakan Sliding Mode Control berbasis PID, untuk menghilangkan efek chattering pada sinyal kontrol.

\section{DESAIN DAN PEMODELAN SISTEM}

Plant coupled tanks merupakan tangki dengan konfigurasi dua tangki atau lebih yang saling berhubungan dengan sebuah pipa atau saluran air seperti pada Gambar 2.6. Adanya hubungan antara tangki ini membuat level cairan pada setiap tangki saling berhubungan atau berinteraksi. Konfigurasi tangki seperti ini banyak digunakan pada industri, seperti industri pembuatan kertas, industri pengolahan limbah, dan industri kimia.

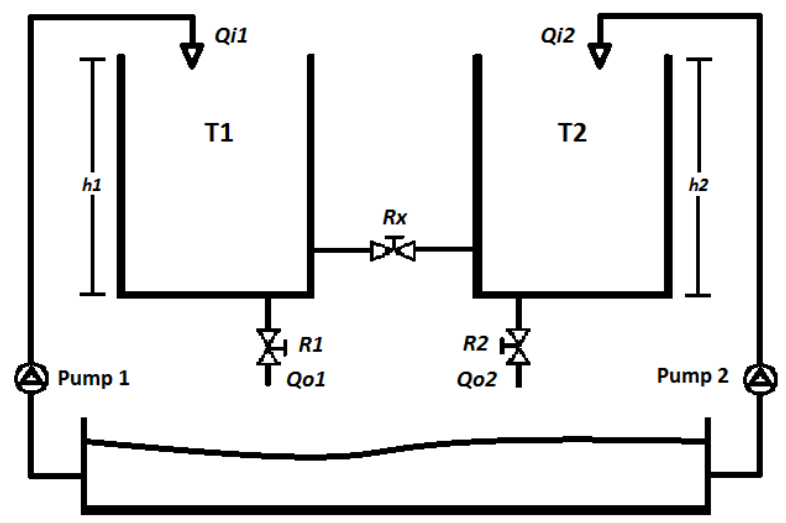

Gambar 1. Model plant coupled tanks

Level cairan pada tangki pertama ditunjukkan sebagai $\mathrm{H}_{1}$ dan $\mathrm{H}_{2}$ untuk level tangki kedua. Flow cairan yang masuk pada tangki dilambangkan sebagai $\mathrm{Q}_{\mathrm{i}}$. Untuk flow cairan yang keluar 
dari tangki ditunjukkan sebagai $\mathrm{Q}_{\mathrm{i} 1}$ untuk tangki pertama, $\mathrm{Q}_{\mathrm{i} 2}$ tangki kedua, dan $\mathrm{Q}_{\mathrm{x}}$ sebagai flow interaksi antara tangki pertama dan tangki kedua. Sistem coupled tanks dapat dikonfigurasikan sebagai sistem Single Input Single Output (SISO), Multi Input Multi Output (MIMO), atau Single Input Multi Output (SIMO) berdasarkan manipulasi masukan pada pompa dan daerah kerja dari rotary valve yang terdapat pada plant coupled tanks. Jika berdasar model pada Gambar 2.1 maka plant ini bisa digolongkan sebagai sistem SIMO karena hanya memiliki satu masukan berupa aliran masuk air pada tangki satu dan untuk keluaran adalah level pada kedua tangki.

\section{A. Pemodelan Sistem Pengaturan Level Plant Coupled Tank [1], [2]}

Sistem yang akan dirancang adalah sistem pengaturan level dengan konfigurasi SISO yaitu pengaturan level pada tangki ke dua, dengan ditunjukkan masukan berupa tegangan pada pompa air untuk memberi aliran air masuk ke tangki dan keluaran berupa level air pada tangki satu atau dua. Model dari plant coupled tank seperti pada Gambar 2.6.

Proses pemodelan dimulai dari pemodelan pompa, pipa, tangki pada plant coupled tanks, dan sensor yang digunakan seperti pada Gambar 2.

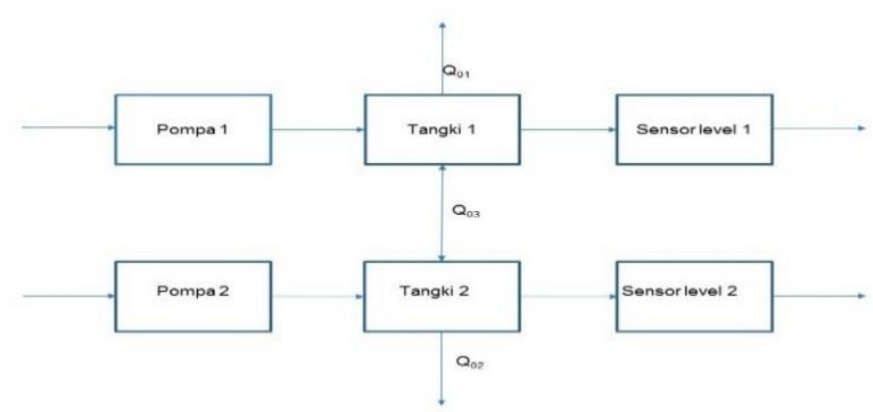

Gambar 2. Diagram Blok Pemodelan Sistem Pengaturan Level

Parameter yang digunakan pada pemodelan sistem pengaturan level ini dapat dilihat pada Tabel 1. Dalam pemodelan suatu sistem diperlukan juga untuk mengetahui karakteristik dari komponen setiap penyusun sistem. Sebagai contoh pada pompa perlu diketahui berapa tegangan maksimal kerja pompa, cara kerja dari pompa. Dengan diketahui dengan detail mengenai karakteristik dari sistem maka model matematis yang akan dibuat bisa lebih akurat dan juga dalam real sistem maka akan diketahui permasalahan yang timbul apabila ada karakteristik dari setiap komponen yang diabaikan.
Tabel 1.

Paramater Pemodelan Plant [3]

\begin{tabular}{clcc}
\hline \hline Simbol & \multicolumn{1}{c}{ Keterangan } & Satuan & Nilai \\
\hline $\mathrm{H}_{1}, \mathrm{H}_{2}$ & $\begin{array}{l}\text { Ketinggian air dalam } \\
\text { tangki 1 dan 2 }\end{array}$ & $\mathrm{cm}$ & 40 \\
$\mathrm{~A}$ & $\begin{array}{l}\text { Luas penampang } \\
\text { Luas penampang } \\
\text { lubang keluaran tangki }\end{array}$ & $\mathrm{cm}^{2}$ & 66,25 \\
& $\begin{array}{l}\text { 1 dan 2 dan saluran } \\
\text { penghubung antara } \\
\text { tangki 1 dan 2 }\end{array}$ & & 0,1963 \\
$\mathrm{a}$ & $\begin{array}{l}\text { Rasio bukaan katup } \\
\text { (valve) pada lubang }\end{array}$ & & \\
& $\begin{array}{l}\text { keluaran tangki 1 dan 2 } \\
\text { Rasio valve antara } \\
\text { tangki 1 dan 2 }\end{array}$ & & 0,35903 \\
$\beta_{1}, \beta_{2}$ & $\begin{array}{l}\text { Gravitasi } \\
\beta_{\mathrm{x}}\end{array}$ & $\mathrm{m}^{2} / \mathrm{s}$ & 9,38705 \\
$\mathrm{~g}$ & $\begin{array}{l}\text { Debit air yang masuk } \\
\text { pada tangki 1 }\end{array}$ & $\mathrm{cm}^{3} / \mathrm{s}$ & 2,88 \\
$Q_{i 1}$ & $\begin{array}{l}\text { Debit air yang masuk } \\
\text { pada tangki 2 }\end{array}$ & $\mathrm{cm}^{3} / \mathrm{s}$ & 2,588 \\
$Q_{i 2}$
\end{tabular}

\section{B. Identifikasi Sistem [1]}

Sistem coupled tank terdiri dari dua tangki vertical interkoneksi oleh saluran aliran air yang menyebabkan ketinggian air dari dua tangki berinteraksi. Setiap tangki memiliki pompa independen untuk masukannya berupa cairan. Luas penampang dari bukaan katup dan dasar dari masingmasing tangki dan saluran menghubungkan dua tangki ini dapat divariasikan dengan rotary valves. Sistem coupled tank ini dapat dikonfigurasikan sebagai SISO (Single Output Single Input) atau dapat juga sebagai sistem MIMO (Multiple Output Multiple Input) melalui manipulasi pompa input dan sectional daerah dari rotary valves.

Berdasarkan hukum kesetimbangan massa, didapat persamaan setiap tangki sebagai berikut:

$$
\begin{aligned}
& A_{1} \frac{d H_{1}}{d t}=Q_{i 1}-Q_{o 1}-Q_{o 3} \\
& A_{2} \frac{d H_{2}}{d t}=Q_{i 2}-Q_{o 2}-Q_{o 3}
\end{aligned}
$$

Dimana $\mathrm{H}_{1}$ dan $\mathrm{H}_{2}$ masing-masing adalahketinggian dari caiaran yang terdapat pada tangki 1 dan tangki 2. Lalu $A_{1}$ dan $\mathrm{A}_{2}$ adalah luas penampang yang dimiliki oleh tangki 1 dan tangki 2. $\mathrm{Q}_{\mathrm{i} 1}$ dan $\mathrm{Q}_{\mathrm{i} 2}$ adalah debit air yang dikeluarkan dari pompa yang masing-masing menuju ke tangki 1 dan menuju ke tangki 2. Sedangkan $\mathrm{Q}_{01}$ dan $\mathrm{Q}_{02}$ adalah debit air keluar yang dimiliki masing-masing tangki 1 dan tangki 2.

Dari persamaan Bernoulli untuk cairan non-kental, kemampatan cairan dalam aliran dapat direpresentasikan sebagai berikut:

$$
\begin{aligned}
& Q_{o 1}=\beta_{1} \cdot a \cdot \sqrt{2 g} \cdot \sqrt{H_{1}} \\
& Q_{o 2}=\beta_{2} \cdot a \cdot \sqrt{2 g} \cdot \sqrt{H_{2}} \\
& Q_{o 3}=\beta_{x} \cdot a \cdot \sqrt{2 g} \cdot \sqrt{H_{1}-H_{2}}
\end{aligned}
$$


Dimana, $\beta_{1}, \beta_{2}$, dan $\beta_{\mathrm{x}}$ merupakan konstanta proporsional dimana bergantung dari koefisien debit air area yang saling silang dan juga konstanta gravitasi. Dengan menggunakan Persamaan (3), Persamaan (4), dan Persamaan (5) ke Persamaan (1) dan Persamaan (2) didapatkan persamaan nonlinear yang menggambarkan dinamika dari multi-input dan multi-output sistem berasal sebagai berikut:

$$
\begin{aligned}
& A_{1} \frac{d H_{1}}{d t}=q_{1}-\frac{\alpha_{1}}{2 \sqrt{H_{1}}} h_{1}-\frac{\alpha_{3}}{2 \sqrt{H_{1}-H_{2}}}\left(h_{1}-h_{2}\right) \\
& A_{2} \frac{d H_{2}}{d t}=q_{2}-\frac{\alpha_{2}}{2 \sqrt{H_{2}}} h_{2}+\frac{\alpha_{3}}{2 \sqrt{H_{1}-H_{2}}}\left(h_{1}-h_{2}\right)
\end{aligned}
$$

Dengan menguji menggunakan sinyal step untuk mendapatkan model non-linear sesuai dengan pengaruh dari tiap masukan dapat didapatkan model plant sebagai berikut:

$$
\begin{aligned}
G_{11} & =\frac{0,7874}{21 s+1} \\
G_{12} & =\frac{0,0946}{31 s+1} \\
G_{21} & =\frac{0,08915}{29 s+1} \\
G_{22} & =\frac{0,7829}{22 s+1}
\end{aligned}
$$

\section{Dekopling [2]}

Dekopling digunakan untuk meminimalisir atau menghilangkan interaksi yang terjadi pada plant coupled tanks yang bersifat MIMO yang menyebabkan terjadinya interaksi input. berikut:

Desain yang digunakan pada plant ditunjukkan seperti

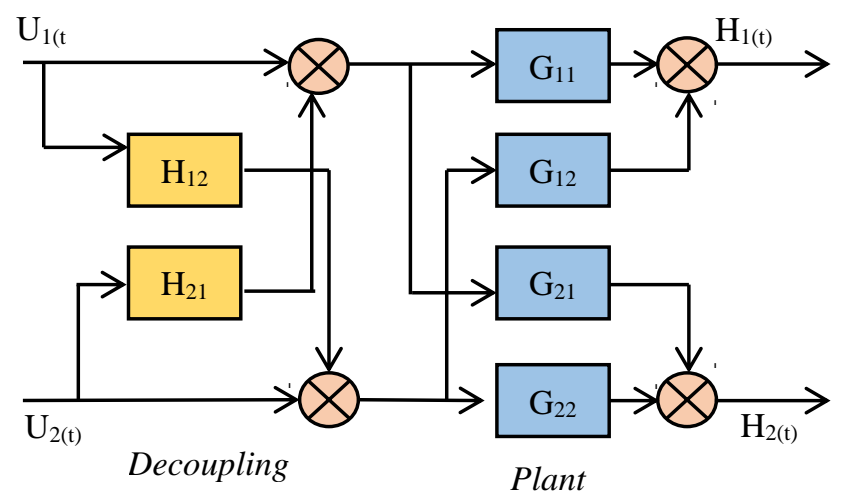

Gambar 3. Plant dengan Decoupling

Didapatkan persamaan untuk decoupling dengan manganalisa secara terpisah pada setiap input-output.

Persamaan $\mathrm{D}_{12}$ didapat dengan cara berikut:
$\left(G_{11} D_{12}+G_{12}\right) X_{2}=0$

$G_{11} D_{12}+G_{12}=0$

$D_{12}=-\frac{G_{12}}{G_{11}}$

Persamaan $\mathrm{D}_{21}$ didapat dengan cara:

$$
\begin{aligned}
& \left(G_{22} D_{21}+G_{21}\right) X_{1}=0 \\
& G_{22} D_{21}+G_{21}=0 \\
& D_{21}=-\frac{G_{21}}{G_{22}}
\end{aligned}
$$

Dengan fungsi alih yang didapatkan dari model di atas masuk ke persamaan berikut:

$$
\begin{aligned}
& G_{1}(s)=G_{11}(s)-D_{12}(s) \cdot G_{12}(s) \\
& G_{1}(s)=\frac{577,7 s^{2}+37,88 s+0,6187}{1,526 e 04 s^{3}+1729 s^{2}+64,2 s+0,7829} \\
& G_{2}(s)=G_{22}(s)-D_{21}(s) \cdot G_{21}(s) \\
& G_{2}(s)=\frac{577,7 s^{2}+37,88 s+0,6187}{1,63 e 04 s^{3}+1816 s^{2}+66,39 s+0,7998}
\end{aligned}
$$

\section{Perancangan Kontroler Sliding Mode [3]}

Perancangan kontroler didesain dan diimplementasikan untuk mempercepat rise time dan menjadikan respon mencapai set point yang diinginkan. Dari Persamaan (14) dan (15) dilakukan pendekatan orde satu menggunakan reduksi bode. Pada hasil identifikasi menggunakan analisa reduksi bode, didapat fungsi alih dari plant seperti berikut:

$$
\begin{aligned}
& g_{1}=\frac{0.788}{20.7 s+1} \\
& g_{2}=\frac{0.771}{21.7 s+1}
\end{aligned}
$$

Dari Persamaan (16) dan Persamaan (17) akan didesain kontroler sliding mode untuk mengendalikan model tersebut. Dimana kontroler ini akan mengatur level dari tangki agar sesuai dengan set point yang diinginkan.

Koefisien dari numerator dan denumerator sebagai fungsi alih dari Persamaan (16) dan Persamaan (17) akan dimisalkan menjadi variabel tetap agar lebih mudah dalam mendesain kontroler. Sehingga fungsi alih dari plant menjadi:

$$
G(s)=\frac{Y(s)}{U(s)}=\frac{K}{a s+b}
$$

Transfer function di atas pada Persamaan (18) dapat direpresentasikan dalam bentuk persamaan diferensial (dengan asumsi nilai awal adalah nol): 


$$
\begin{aligned}
& a \dot{y}+b y=K u \\
& \dot{y}=c y+d u \\
& \ddot{y}=c \dot{y}+d \dot{u}
\end{aligned}
$$

Dimana

$$
\begin{aligned}
& c=-\frac{b}{a} \\
& d=\frac{K}{a}
\end{aligned}
$$

Lalu, ambil persamaan sinyal error

$$
e=y_{r}-y
$$

Didefinisikan suatu permukaan luncur sebagai berikut:

$$
\begin{aligned}
& \sigma_{s}=\alpha e+\dot{e} \\
& \dot{\sigma}_{s}=\alpha \dot{e}+\ddot{e}
\end{aligned}
$$

Sehingga didapat persamaan untuk Ueq seperti berikut:

$$
u_{e q}=\frac{\dot{y}_{r}}{d}-\frac{c y}{d}+\frac{\ddot{y}_{r}}{\alpha d}-\frac{c \dot{y}}{\alpha d}-\frac{\dot{u}_{e q}}{\alpha}
$$

Setelah ditemukan sinyal kontrol ekivalen, selanjutnya adalah mencari sinyal kontrol natural.

$$
\dot{\sigma}_{s}=\alpha \dot{y}_{r}-\alpha c y-\alpha d u+\ddot{y}_{r}-c \dot{y}-d \dot{u}
$$

Dimana

$$
u=u_{e q}+u_{n}
$$

Berdasarkan syarat kestabilan Lyapunov, maka dipilih:

$$
\dot{\sigma}_{s}=-W \cdot \operatorname{sat}\left(\sigma_{s}\right)
$$

Sehingga $U n$ didapatkan sebagai berikut:

$$
u_{n}=\frac{W}{\alpha d} \cdot \operatorname{sat}\left(\sigma_{s}\right)-\frac{\dot{u}_{n}}{\alpha}
$$

Dimana $\mathrm{W}>0$.

\section{HASIL SIMULASI}

Pada bab ini, dipaparkan hasil simulasi dan analisis dari open loop system dan Sliding Mode Control.

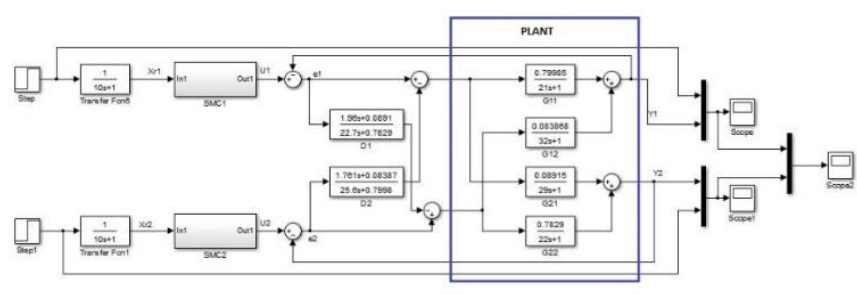

Gambar 3. Desain Kontroler SMC

\section{A. Pengujian Open Loop System}

Pada tahap ini dilakukan simulasi sistem plant coupled tank pada tangki 1 dan 2. Respon open loop dilakukan untuk menguji respon plant coupled tank apabila tidak dilakukan proses control close loop. Dari persamaan fungsi alih $\mathrm{G}_{11}, \mathrm{G}_{12}, \mathrm{G}_{21}$, dan $\mathrm{G}_{22}$ dilakukan pengujian open loop tanpa diberi kontroler terlebih dahulu seperti yang terlihat pada Gambar 4.

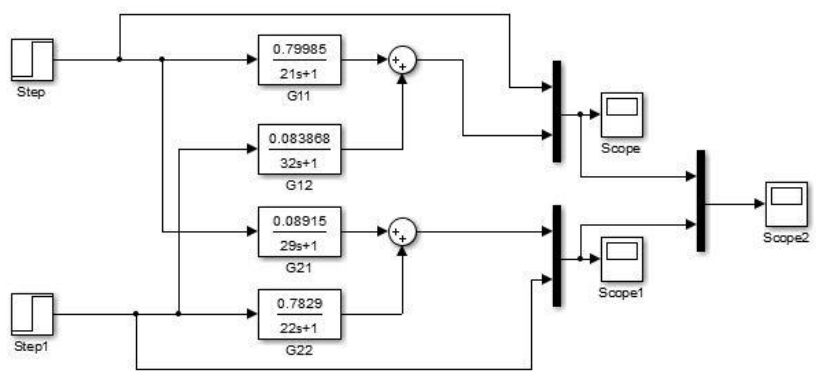

Gambar 4. Diagram Simulasi Sistem Open Loop tanpa Decoupling

Yang pertama, dilakukan simulasi pada plant tangki 1. Sinyal uji yang diberikan berupa sinyal step dengan set point lima. Hasil simulasi didapatkan respon sistem seperti pada Gambar 5.

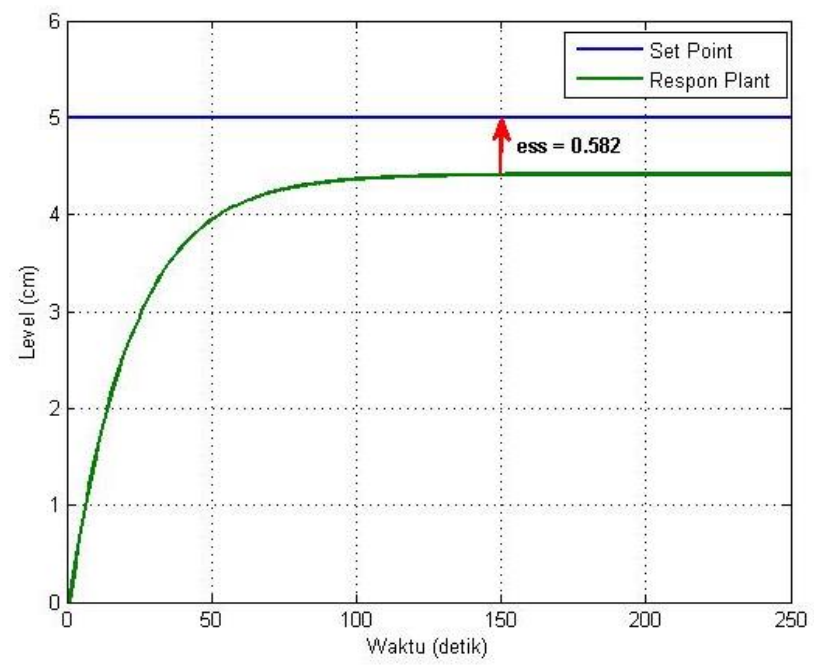

Gambar 5. Respon Sistem Open Loop tanpa Decoupling Tangki 1

Dari respon sistem pada Gambar 5 tersebut dapat diamati bahwa sistem open loop tanpa decoupling tangki 1 masih memiliki kesalahan tunak, yaitu sebesar 0.582. Selanjutnya dilakukan simulasi pada tangki 2 . Sinyal uji yang diberikan sama dengan sinyal uji yang diberikan pada plant tangki 1 . 
Hasil simulasi didapatkan respon sistem seperti pada Gambar 6.

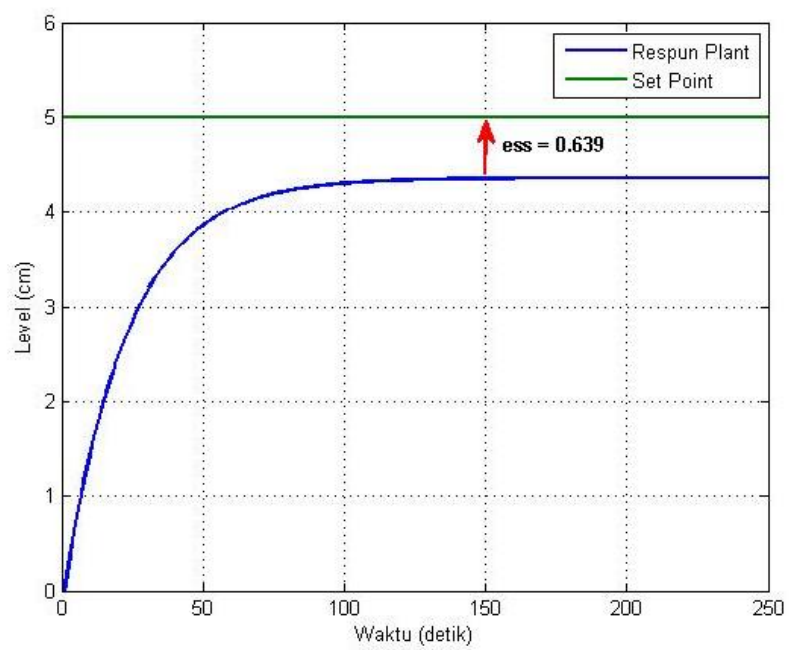

Gambar 6. Respon Sistem Open Loop tanpa Decoupling Tangki 2

Dari respon sistem pada Gambar 6 tersebut dapat diamati bahwa sistem open loop tanpa decoupling tangki 2 masih memiliki kesalahan tunak, yaitu sebesar 0.639 .

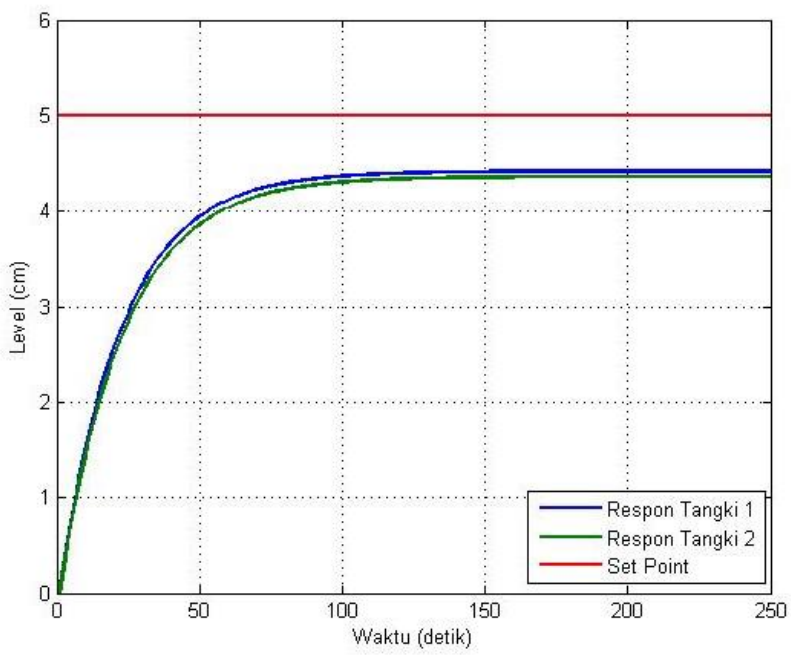

Gambar 7. Respon Sistem Open Loop tanpa Decoupling Tangki 1 dan 2

Dari Gambar 7 dapat dilihat saat kedua tangki mendapatkan sinyal uji yang sama mempunyai perbedaan waktu tunak. Dimana kesalahan tunak dari tangki 1 lebih kecil dibandingkan dengan kesalahan tunak dari tangki 2.

\section{B. Pengujian Kontroler SMC-PID}

Pada tahap ini dilakukan pengujian pada plant coupled tank pada tangki 1 dan tangki 2 dengan menggunakan sinyal uji berupa sinyal step. Berikut ini merupakan hasil pengujian pada tangki 1 adalah sebagai berikut:

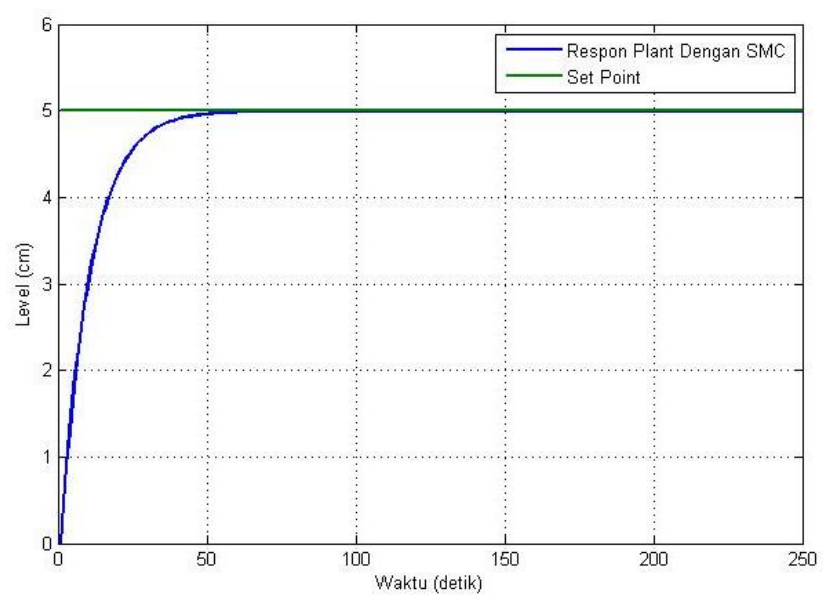

Gambar 8. Respon pada Tangki 1 dengan Sliding Mode Controller

Dari Gambar 8 dapat dilihat bahwa respon tersebut mulai steady state pada waktu 60 detik dan mempunyai rise time sekitar 30 detik.

Selanjutnya dilakukan pengujian pada tangki 2 dengan menggunakan sinyal uji berupa sinyal step. Berikut ini adalah hasil pengujian pada tangki 2 .

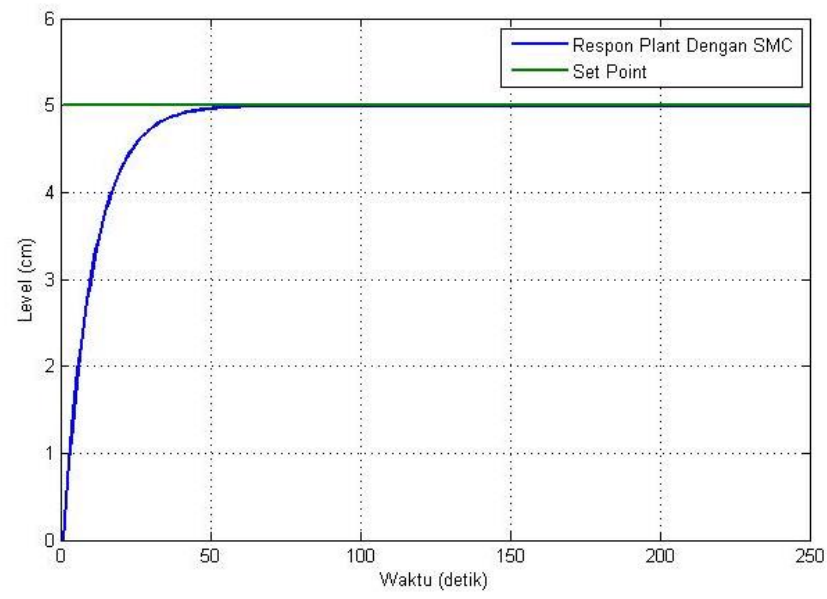

Gambar 9. Respon pada Tangki 2 dengan Sliding Mode Controller

Dari Gambar 9 dapat dilihat bahwa respon tersebut mulai steady state pada waktu 67 detik dan mempunyai rise time sekitar 34 detik.

\section{KESIMPULAN}

Berdasarkan hasil pengujian dan analisis, dapat diperoleh kesimpulan bahwa Metode Sliding Mode Control yang diaplikasikan pada plant coupled tanks dengan time constant mendekati respon orde pertama yang diinginkan. Dari kontroler didapatkan error sebesar $0,042 \%$ pada tangki 1 dan $0,047 \%$ pada tangki 2. 


\section{DAFTAR PUSTAKA}

[1] Darmawan, Rheza Qashmal, "Desain Autotuning Kontroler PID Berbasis Algoritma Neural-Network Untuk Sistem Pengaturan Cascade Level dan Flow Liquid pada Plant Coupled Tanks", Tugas Akhir, Jurusan Teknik Elektro ITS Surabaya, 2016.

[2] Arjin Numsomran, Tianchai Suksri, Maitree Thumma, "Design of 2-DOF PI Controller with Decoupling for Coupled-Tank Process", International Conference on Control, Automation and Systems, 2007.

[3] Al Amin, Anas, "Pengaturan Tekanan Boiler-Turbine Berbasis Hybrid Fuzzy PID.", Tugas Akhir, Jurusan Teknik Elektro ITS Surabaya, 2012. 